\title{
The rise of cholesterol testing: how much is unnecessary?
}

\author{
Helen Doll, Brian Shine, Jonathan Kay, Tim James, Paul Glasziou
}

\begin{abstract}
Background

Laboratory testing has increased dramatically over recent decades, which is a consequence particularly of repeat testing or monitoring, as either a response to
\end{abstract} treatment or follow-up.

Aim

To assess rates of measurement of lipid levels (total cholesterol, high-density lipoprotein, triglyceride) for diagnosis and monitoring over the last 20 years.

Design of study

Audit of electronic database.

Setting

A single region in the UK (Oxfordshire).

\section{Method}

Specimens from individual patients were matched over time. All tests that were the third or more in a 3-year period were considered to be for monitoring, while the first and second were considered to be for diagnosis. As recent evidence-based recommendations suggest that frequent monitoring of cholesterol may reflect measurement error rather than true changes, between one and three tests in each 3-year period were considered to be 'necessary'.

\section{Results}

Over the 20 years from 1987 there has been a more than 15 -fold rise in the overall number of lipid tests requested. After a small decline in the early 1990s, testing rose steadily after publication of several large statin trials, particularly tests requested in primary rather than secondary care. Repeat testing (likely to be for monitoring) rose from $24 \%$ of tests (1993-1995) to $61 \%$ (2005-2007), with between $42 \%$ and $79 \%$ of tests in 2005-2007 possibly being unnecessary. Mean cholesterol values declined over time from 1996 onwards.

\section{Conclusion}

In the last decade, the number of cholesterol tests performed in Oxfordshire has risen dramatically. Much of this appears to be for monitoring purposes rather than case finding or risk assessment. The majority of cholesterol tests requested may be unnecessary.

\section{Keywords}

cholesterol; laboratories, hospital; patient monitoring; testing, lipid; statin.

\section{INTRODUCTION}

The use of laboratory tests has increased dramatically over the last decades. While some of this increase has provided clinical benefits, some also reflects inappropriate test ordering. ${ }^{1-4}$ Repeat testing is a major, and growing, component of all laboratory testing, ${ }^{5}$ with at least some likely to be unnecessary. ${ }^{6}$ Although the repeat testing may be for relatively simple tests, the high volume of such tests makes the issue important.

Lipid measurement is essential for calculating an individual's overall risk of coronary heart disease $(\mathrm{CHD}):^{7,8}$ high total cholesterol, ${ }^{9}$ high low-density lipoprotein (LDL), ${ }^{10}$ and low high-density lipoprotein $(\mathrm{HDL})^{11}$ cholesterol are associated with increased risk. The risk-prediction charts of the Joint British Societies use total cholesterol or the total-to-HDL cholesterol ratio, ${ }^{7}$ making these the most commonly measured blood lipids. LDL may be measured directly, but is more commonly calculated using the Friedewald formula, which requires triglyceride measurement. ${ }^{12}$

Introduced in 1987, statins (or 'HMG-CoA reductase inhibitors') have made a dramatic difference to lipid management, being particularly

H Doll, BSc, MSc, DPhil, senior medical statistician; P Glasziou, FRACGP, MRCGP, PhD, professor of evidencebased medicine, Department of Primary Health Care, University of Oxford. B Shine, MD, FRCPath, consultant chemical pathologist; J Kay, MA, MSc, MB, BS, FRCPath, consultant chemical pathologist; T James, BSc, MSc, PhD, FIBMS, head biomedical scientist, Department of Clinical Biochemistry, Oxford Radcliffe Hospitals NHS Trust, Oxford.

Address for correspondence

Dr Helen Doll, Department of Primary Health Care, University of Oxford, Old Road Campus, Roosevelt Drive, Headington, Oxford, OX3 7LF.

E-mail: Helen.doll@dphpc.ox.ac.uk

Submitted: 27 November 2009; Editor's response: 18 January 2010; final acceptance: 25 May 2010.

(C)British Journal of General Practice

This is the full-length article (published online 31 Jan 2011) of an abridged version published in print. Cite this article as: Br J Gen Pract 2011; DOI: 10.3399/bjgp11X556245. 
effective in reducing LDL cholesterol. ${ }^{13}$ Cholesterol lowering using statins reduces $\mathrm{CHD}$ mortality among those at both moderate and high risk of $\mathrm{CHD},{ }^{14-21}$ with moderate risk defined as $15-30 \%$ and high risk as $\geq 30 \%$ for a 10 -year CHD event. ${ }^{7,22}$

The number of statin prescriptions has grown by $30 \%$ annually, with UK statin expenditure increasing from around £20 million in 1993 to over $£ 113$ million in $1997,{ }^{18}$ and to $£ 700$ million in 2004 , representing $9.1 \%$ of prescription costs of the National Health Service (NHS). ${ }^{23}$ Atorvastatin and simvastatin represent the top two drug costs in England ( $£ 360$ and £251 million respectively). ${ }^{24}$ National Institute for Health and Clinical Excellence 2006 guidelines propose the use of statins for both primary and secondary prevention of $\mathrm{CHD}$, stating that the statin with the lowest acquisition costs should be used. ${ }^{25}$ The annual NHS bill for statins was predicted to have been more than £2 billion in 2010. ${ }^{23}$

Whether the rise in statin usage has been paralleled by a rise in cholesterol testing and monitoring has not been systematically studied. Cholesterol tests account for about $2.5 \%$ of al biochemical tests, and treatment guidelines recommend at least annual monitoring of lipid levels for patients on lipid-lowering therapy. ${ }^{26}$ However, it has been suggested that, because of the weak signal-to-noise ratio in measuring cholesterol level, frequent monitoring of cholesterol might reflect measurement error rather than true changes, ${ }^{6}$ and less frequent testing of cholesterol, such as every 3 to 5 years, might be warranted in compliant patients who have reached their target levels: it took almost 4 years for long-term variation to exceed short-term variation. ${ }^{6}$ Results were similar in apparently healthy patients not taking cholesterol-lowering medication. ${ }^{27}$ This implies that testing of both at-target treated and healthy non-treated patients more than once every 3 years may be unnecessary.

This study examined the patterns of cholesterol testing within Oxfordshire, UK, over a 20-year period from 1987 to 2007 . This study aimed to: (1) report the change in the number of cholesterol tests during the 20-year period by source (primary or secondary care) and patient demographics (age, sex); (2) calculate the number of tests by 3 -year period and estimate the proportion of tests for monitoring rather than diagnosis, and the proportion that may be unnecessary; and (3) relate frequency of testing to estimated changes in mean cholesterol levels.

\section{METHOD}

The Department of Clinical Biochemistry at the Oxford Radcliffe Hospitals NHS Trust serves the population of Oxfordshire and parts of several neighbouring counties (primary and secondary care),

\section{How this fits in}

Counter to common perception, the pattern of laboratory testing of lipids shows

a close link to publication of research and guidelines. A slight fall in testing

followed the call for a moratorium on cholesterol treatment published in the

British Medical Journal; then in the mid-1990s the publication of the major statin

trials was followed by a steep rise in testing that preceded guidelines and the

quality frameworks. There are several clinical messages: appropriate testing has

increased and cholesterol levels appear to be lowered, particularly in older

patients (appropriately so). However, based on recent evidence-based

recommendations, there also appears to be considerable over-monitoring that is

straining laboratories without necessarily benefiting patients.

as well as tertiary care for several counties. The service is provided through laboratories within the John Radcliffe and Churchill hospitals in Oxford and the Horton Hospital in Banbury. The Department performs more than 5.7 million tests a year, and has an ' $M$ '-based laboratory information management system with complete data going back to the mid1980s. The standard laboratory practice throughout the period was to undertake all of, and only, those tests ordered by the requesting clinician.

The laboratory information management system was searched for all total cholesterol, HDL cholesterol, and triglyceride measurements over the period from 1987 to 2007 . For each specimen, the patient's hospital or NHS number (where known), and their surname, forename, sex, date of birth, the date of the specimen, the requesting physician, and his/her location were also recorded. As consultant head of the Department of Clinical Biochemistry, one of the researchers has full access to the data; no one outside the department was given access to data that were not fully anonymised or aggregated.

The NHS number was used to link records. For the $5 \%$ of records overall with no NHS number (the proportion was greater in earlier years), patients' surname, forename, sex, and date of birth were used to match with those already linked using NHS numbers. Data were then anonymised. For each patient, the dates of the first and last specimens, and the number of specimens in each year were determined. Data were then considered in 3-year periods. While the purpose of tests (screening or monitoring) was not recorded, in each 3-year period all tests beyond the second (third and subsequent specimens) were considered likely to be for monitoring rather than diagnosis: either as a response to treatment or for longer-term follow-up.

Similarly, it was not known which patients were being treated and, of these, which were at target. A sensitivity analysis was used to estimate a range of possible values for the proportion of unnecessary tests, assuming that only the first test in each 3-year 


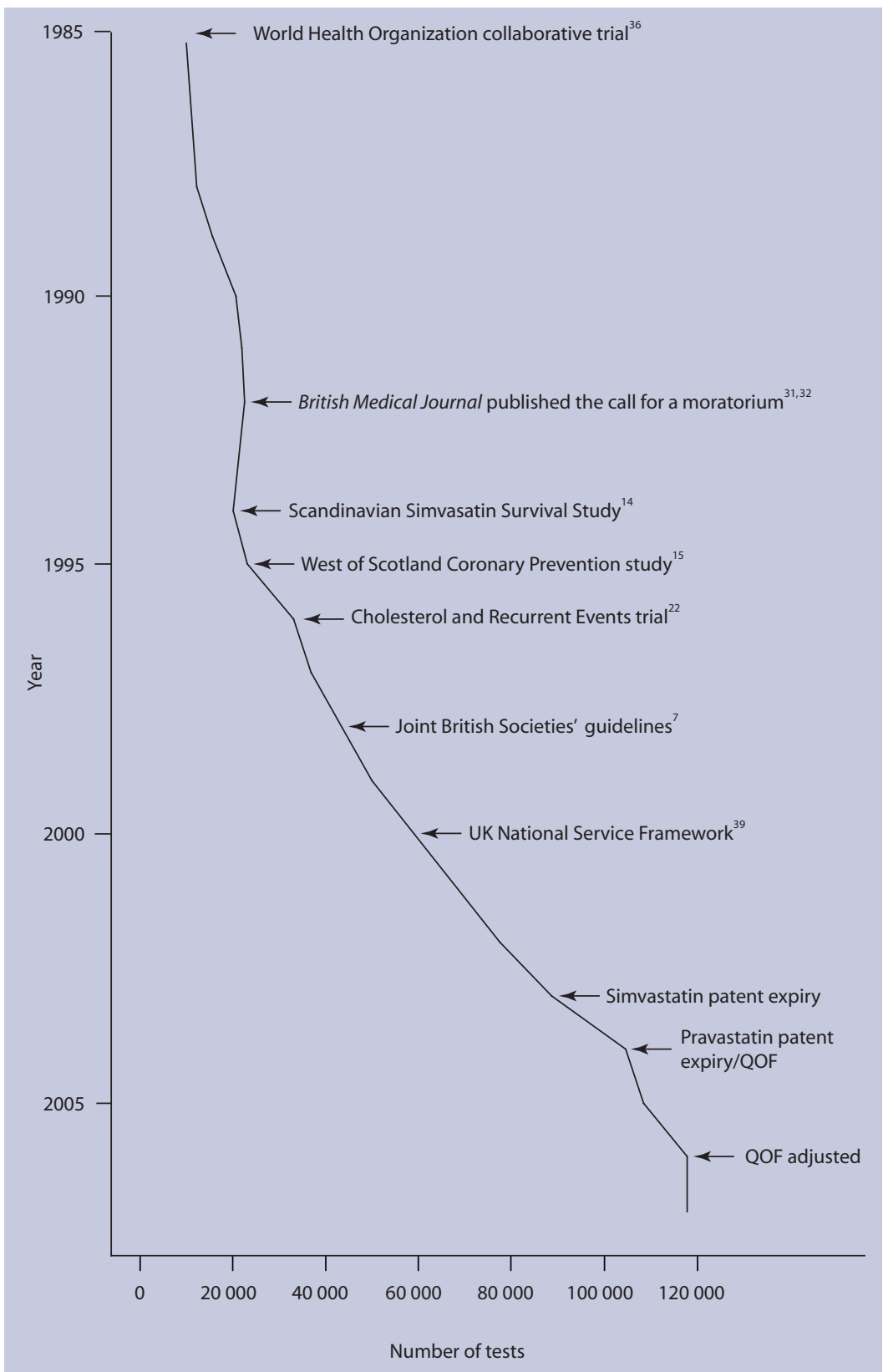

Figure 1. Number of total cholesterol tests requested from 1987 to 2007 in Oxfordshire, UK and dates of key guidelines and statin trial publications. QOF = Quality and Outcomes Framework. period may be necessary for patients, both treated and untreated, who are at target ${ }^{6,27}$ while for those patients who have yet to attain target levels, more frequent (for example, annual ${ }^{26}$ ) testing may be warranted. The proportion of unnecessary tests was thus estimated to lie between the fourth or more (that is, those tests that were more frequent than annual) to the second or subsequent tests in each 3-year period. As the individuals in the sample will have comprised both those who were at target and those who were not, the true value, based on current evidence-based recommendations, is likely to lie within this range.

\section{Statistical methods}

Data were analysed using $R^{28}$ To assess factors related to cholesterol level, a series of maximum likelihood mixed effects linear regression models were fitted to the data. ${ }^{29}$ These models allow for correlation between repeated measurements and for both fixed and random effects. Person ID was fitted as a random effect; fixed effects included sex, age, and age-squared (to allow for the observed nonlinearity of the relationship between age and cholesterol), time since first test, specimen number, testing period (up to 1995 versus after 1995), and the interaction between specimen number and testing period.

\section{RESULTS}

Over the two decades, the number of total cholesterol requests per year increased more than 10-fold from 10193 in 1987, to 117488 in 2007 (Figure 1). During the early 1990s there was a slight fall in the number of total cholesterol tests requested, followed by a rapid four-fold rise from 1996 onwards. The largest absolute increases in specimen requests occurred during 2003 (11305 tests) and 2004 (15 888 tests). The increase in triglyceride requests was similar (7180 in 1987 to 85885 in 2007; an almost 11-fold increase), but much greater for HDL cholesterol (nine tests in 1987, and 1081 in 1995, to 88356 in 2007; an 81-fold increase from 1996 onwards; Figure 2).

Over all analyses, the increase to 291729 tests in 2007 was almost 16-fold from 1987 (17 382 tests) and more than seven-fold from 1996 onwards (35 988 tests in 1995). Within each age group, the number of specimens generally increased over time. However, the increase was smallest in those aged $<30$ years (7953 specimens requested in 1987-1989 versus 30256 in 2005-2007; a relative increase of almost three-fold) and greatest in patients in their seventh (8580 versus 84186 ; relative increase almost nine-fold) and eighth decades (3095 versus 77 794; 24-fold).

For all three analyses, most of the increase in requests originated from requests made in primary rather than secondary care: 28 -fold versus 1.8 -fold for total cholesterol, 26-fold versus 1.9-fold for triglycerides (both 1987 to 2007), and 223-fold versus 81-fold for HDL (1992 to 2007) respectively (Figure 2). The proportion of specimens from females increased from $40 \%$ to $50 \%$ over this 20 -year period.

\section{Tests per person}

Of 355517 individuals identified, the number having a first recorded cholesterol test per 3-year period increased from 25538 in 1987-1989 to a peak of 77465 in 2002-2004. The median age at time of first specimen and proportion of females increased from 52 years and $44 \%$ in 1987-1989, to 60 years and $49 \%$ in 2005-2007. Figure 3 shows the overall 
Table 1. Number (\%) of specimens from all 355517 patients having the specified number of tests per 3-year period.

\begin{tabular}{ccccccc}
\hline 3-year period & \multicolumn{2}{c}{ Diagnosis } & Monitoring & Total & \multicolumn{2}{c}{ Sensitivity analysis of unnecessary testing } \\
\hline & 1 test & 2 tests & $\geq 3$ tests & All tests & Lower bound $\geq 2$ tests & Upper bound $\geq 4$ tests \\
\hline $1987-1989$ & $19666(53)$ & $6788(18)$ & $10519(28)$ & 36973 & $17307(47)$ & $6466(17)$ \\
\hline $1990-1992$ & $31870(49)$ & $11658(18)$ & $20869(32)$ & 64397 & $32527(51)$ & $13201(20)$ \\
\hline $1993-1995$ & $36608(57)$ & $12734(20)$ & $15270(24)$ & 64612 & $28004(43)$ & $8373(13)$ \\
\hline $1996-1998$ & $48524(43)$ & $20794(18)$ & $43579(39)$ & 112897 & $64373(57)$ & $29362(26)$ \\
\hline $1999-2001$ & $65298(37)$ & $32890(19)$ & $77369(44)$ & 175557 & $110259(63)$ & $53678(31)$ \\
\hline $2002-2004$ & $76548(28)$ & $52248(19)$ & $140785(52)$ & 269581 & $193033(72)$ & $96352(36)$ \\
\hline $2005-2007$ & $73031(21)$ & $59780(17)$ & $209963(61)$ & 342774 & $269743(79)$ & $143417(42)$
\end{tabular}

${ }^{a}$ Data are broken down by those specimens assumed to be for diagnosis (1-2 tests) and those for monitoring (3+ tests), with a sensitivity analysis showing limits of the numbers of tests that may be unnecessary. numbers of tests, and numbers of tests per person, performed over each 3-year period. The height of each bar corresponds to the overall number of tests performed, with each bar broken down by the proportion of each number of tests per person within that period (one to six and more tests).

In 1987-1989, 19666 people (77\% of the total number of people) had one test, approximately half $(53 \%)$ of the total number of tests (36 973) performed during these 3 years (Table 1). While the proportion of people with one test decreased to $48 \%$ in 2005-2007 (21\% of 342774 tests), the overall number of individuals having one test increased to 73 031. At the same time, the proportion of those having five or more tests increased from $2.3 \%$ in 1987-1989 (597 individuals having 4346 tests) to $9.9 \%$ in 2005-2007 (15 151 individuals having 93757 tests). The tests requested in these $9.9 \%$ of individuals accounted for $27 \%$ of all tests during this last 3-year period.

\section{Monitoring versus diagnosis}

The number and percentage of tests likely to be for monitoring (three or more tests) or diagnosis (one or two tests) within each 3-year period are shown in Table 1 and Figure 3. Between 1987 and 1989, 12\% of patients had three or more tests (31\% of tests). This proportion stayed relatively constant, or even decreased slightly to $24 \%$ in 1993-1995, until 1996-1998 when it began to increase, with $44 \%$ of the tests in 1999-2001 and $61 \%$ of the tests in 2005-2007 being for monitoring.

\section{Necessary versus unnecessary tests}

The proportion of tests in this dataset that were potentially unnecessary ranged from $17 \%$ ( $\geq 4$ th test) to $47 \%$ ( $\geq 2$ nd test) in 1987-1989, fell in 1993-1995 to $13-43 \%$, and rose to $42-79 \%$ in $2005-2007$, which represents between 143417 and 269743 unnecessary tests during the last 3 -year period (Table 1).

\section{Changes in mean cholesterol}

Mean cholesterol levels fell over the period from 6-7 mmol/l in 1987 to around $5.0 \mathrm{mmol} / \mathrm{l}$ in 2007 . The levels had a non-linear relationship with age, with the values peaking at 60-69 years. Figure 4 shows the mean total serum cholesterol values and standard deviation bars stratified by number of tests and 3-year period. Mean cholesterol levels are generally higher in those having more tests before 1999-2001, and lower after this. The solid line in Figure 4 shows the mean cholesterol level over the 3year periods for those being tested for diagnosis only (one or two tests per period), while the dotted line shows levels for those whose tests were assumed to be for monitoring. Levels associated with monitoring decreasing markedly over time, reaching lower values than those for the accompanying diagnostic tests during 2005-2007. Mean cholesterol levels at each test for patients with increasing numbers of specimens within each 3-year period are shown in Figure 5. Mean values generally decrease with each additional test in each 3-year period, and in all but the later years are higher the greater the overall
Figure 2. Number of total cholesterol, triglyceride, and high-density lipoprotein (HDL) cholesterol tests requested per year by primary care (open bar areas) and areas). secondary care (shaded bar

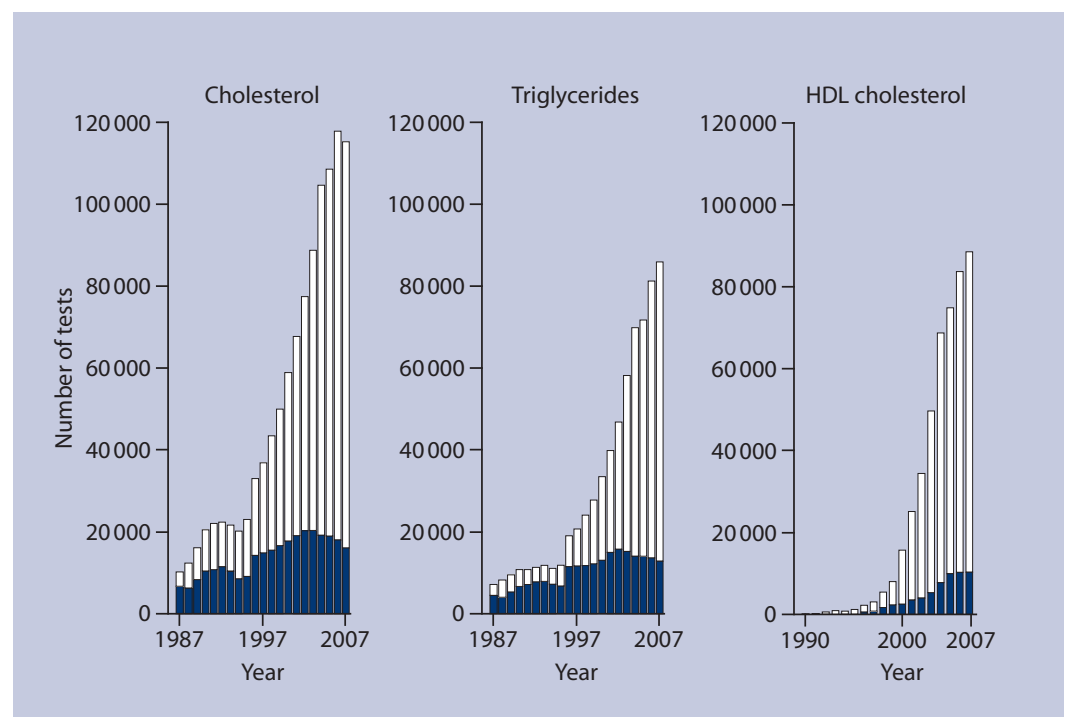




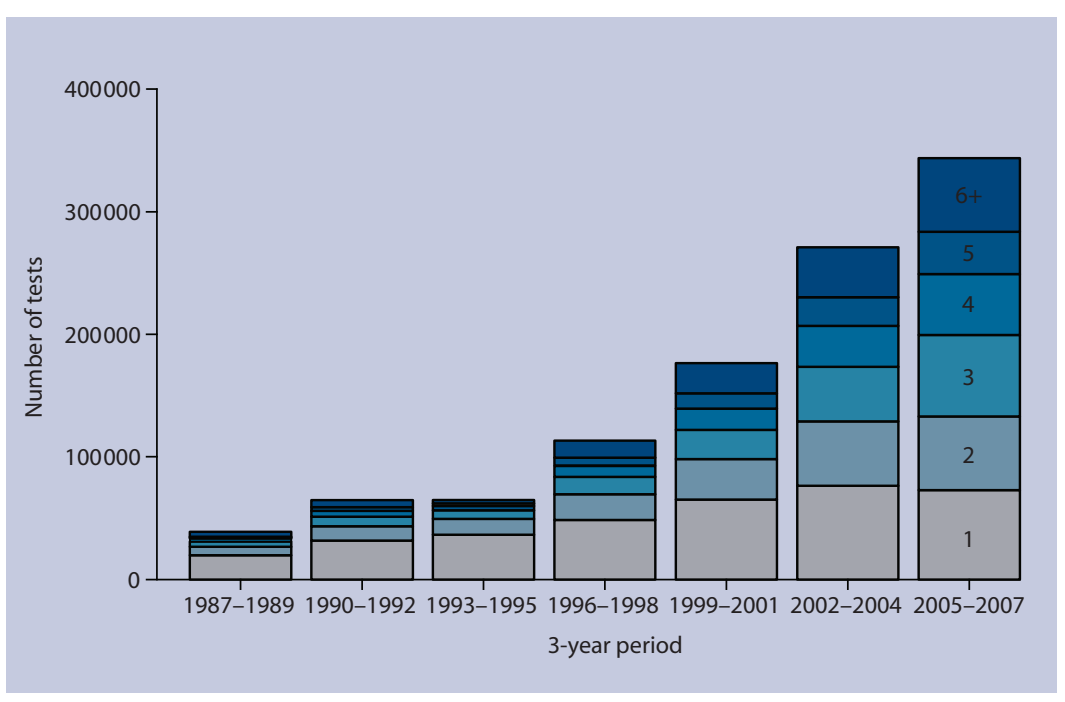

Figure 3. Total number of tests performed per 3-year period, broken down within each bar by frequency of testing $(1,2,3,4,5, \geq 6$ tests per person: the darker the shading the greater the test frequency). Tests performed on a total of 355517 individuals.

number of tests requested.

The mixed models showed that cholesterol was associated with sex (mean levels in males were $0.53 \mathrm{~mm} / \mathrm{l}$ lower), age (patients in middle age generally having higher cholesterol levels: every year of age increased cholesterol by a mean of 0.103 $\mathrm{mmol} / \mathrm{l}$, with the non-linearity of the age effect indicated by every age-squared decreasing the cholesterol level by a mean of $0.001 \mathrm{mmol} / \mathrm{l})$, number of specimens (with every extra specimen per 3-year period increasing the cholesterol by a mean of 0.011 $\mathrm{mmol} / \mathrm{l}$ ), period of testing (cholesterol levels lower after 1995, by a mean of $0.77 \mathrm{mmol} / \mathrm{l})$, and time since first test (cholesterol decreased by a mean of 0.086 $\mathrm{mmol} / \mathrm{l}$ every year). Because of the large sample size, each estimate is precise and highly statistically significant $(P<0.0001)$.

The changing pattern of the relationship between specimen number and mean cholesterol in the later compared with the earlier periods (Figures 4 and 5) was shown by a significant interaction term between specimen number and period, which indicated that after 1995 each additional specimen was associated with a mean reduction in cholesterol of $0.02 \mathrm{mmol} / \mathrm{l}$. This is an overall effect; the reduction is greater in later periods (Figure 4). The mean overall decrease of $0.49 \mathrm{mmol} / \mathrm{l}$ associated with specimens collected after 1995 remained, together with the overall relationship between number of specimens and cholesterol values (every extra specimen was associated with a mean increase in cholesterol of $0.03 \mathrm{mmol} / \mathrm{l})$.

\section{DISCUSSION}

\section{Summary of main findings}

The number of cholesterol tests (total cholesterol, triglycerides, and HDL cholesterol) performed in Oxfordshire fell briefly then rose dramatically over the past 20 years, with a more than 15 -fold increase overall and a 7-fold increase over the last decade. The fall and rise appear to follow closely the publication of systematic reviews, trials, and guidelines. Most of the increase is associated with requests made by primary rather than secondary care, from an increase in testing of older rather than younger patients, and from an increase in the number of tests for monitoring purposes rather than case finding or cardiovascular disease risk assessment. Over the last two decades, the estimated proportion of tests for monitoring has more than doubled from $28 \%$ to $61 \%$. Similarly, the proportion of all tests in this dataset that are potentially unnecessary was estimated to be between $17 \%$ and $47 \%$ in $1987-1989$, rising to between $42 \%$ and $79 \%$ in $2005-2007$. Mean blood cholesterol levels decreased overall from $6.3 \mathrm{mmol} / \mathrm{l}$ in $1987-1989$ to $5.0 \mathrm{mmol} / \mathrm{l}$ in 2005-2007.

\section{Strengths and limitations of the study}

The strengths of the study include the single electronic database with records of laboratory tests conducted in most of Oxfordshire (and surrounding counties for tertiary care) going back to the mid1980s. The high proportion of patients who could be identified reliably using their NHS numbers allowed patient data to be linked over time, estimation of the proportion of tests during each 3-year period conducted for monitoring rather than diagnostic purposes, and, based on recent evidence-based recommendations, ${ }^{6,27}$ the proportion of tests that may have been unnecessary.

The study has some limitations. First, patient identification was imperfect: in earlier years in particular it relied on name, sex, and date of birth. Second, the use of frequency of testing to determine which specimens were obtained for monitoring and which were obtained for diagnosis is subject to error. While the use of name, sex, and date of birth to match patient records with no NHS numbers means that the repeat rate may have been underestimated because of failure to match people with slightly different spellings of names or extra given names (for Ann versus Ann Margaret), equally, some tests may have been repeated for reasons such as the lack of a fasting blood sample, patient movement between practices, or, for patients admitted to secondary care, repeat of a test already undertaken in primary care. Third, there was no information about the patients' histories and risk factors, and it is not known which patients were on treatment and whether or not their target level of cholesterol was reached. Thus, it is not possible to adjust for these factors, all of which would influence monitoring intensity. Fourth, a change in the calibration of the testing around 1993 led to an artificial fall in reported 
cholesterol levels. ${ }^{30}$ Fifth, these data represent only the specimens requested by GPs and hospitals within the region and do not represent population values for Oxfordshire. Sixth, there is no information on cholesterol measurements undertaken in other laboratories, or with point-of-care devices, or of their contribution to changes in laboratory activity.

\section{Comparison with existing literature}

The modest fall in the number of cholesterol tests in the early 1990s followed by the rapid rise in the late 1990s coincides with journal publications and the advent of statin treatment (Figure 1). The fall appears to reflect the questioning of cholesterol treatments, notably the call for a moratorium on cholesterol treatment published by the British Medical Journal. . $^{31,32}$ At that time, no clinical trial convincingly showed that reducing cholesterol levels decreases mortality, with many clinical trials ${ }^{33}$ and, particularly, observational studies, ${ }^{34}$ reporting associated increases in noncardiac mortality. Even though studies such as the Framingham Study, ${ }^{35}$ the Multiple Risk Factor Intervention Trial, and the World Health Organization European Collaborative trial ${ }^{36}$ demonstrated the link between high blood cholesterol and CHD, and specific migrant studies showed the effect of environmental change in raising cholesterol levels with associated higher rates of $\mathrm{CHD},{ }^{37}$ the high prevalence of raised cholesterol levels suggested to some that such levels were biologically normal. ${ }^{38}$

The rise in testing appears to follow the publication of three clinical trials in the mid-1990s, with an initial slight increase following the 1994 publication of the Scandinavian Simvasatin Survival Study, ${ }^{14}$ the first trial to show that a statin could improve survival in

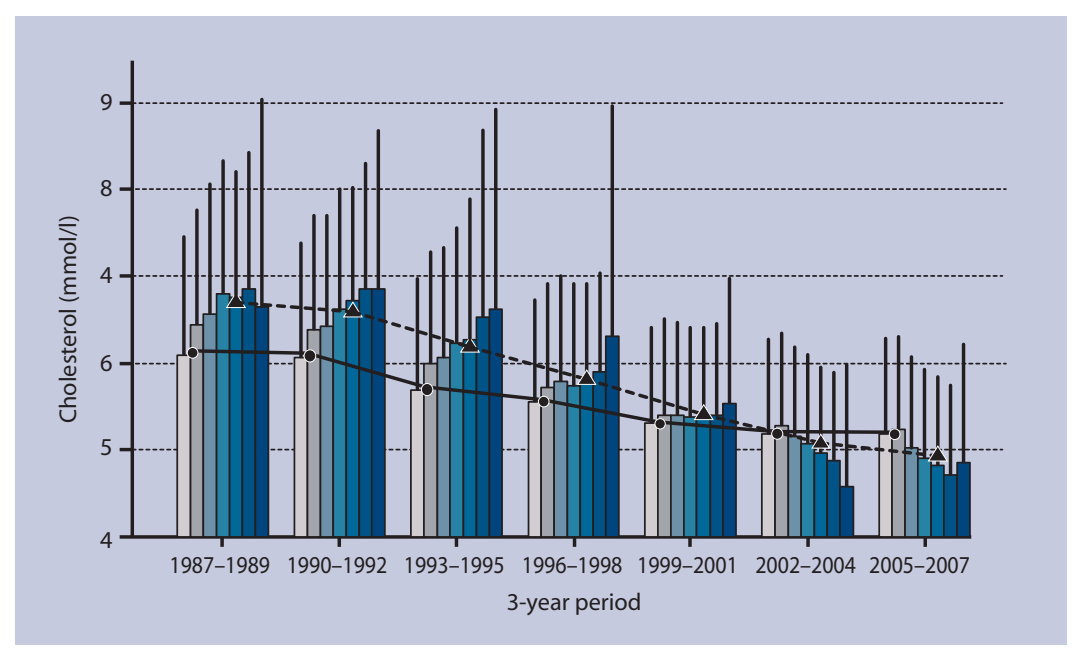

CHD patients. Further rises occurred after the 1995 publication of the West of Scotland Coronary Prevention study ${ }^{15}$ - the first trial to show effectiveness in the primary prevention of $\mathrm{CHD}$ among those with high cholesterol levels - and the 1996 Cholesterol and Recurrent Events trial, ${ }^{22}$ which showed beneficial effects in those with $\mathrm{CHD}$ and moderate cholesterol levels. The rise in testing continued with the Joint British Societies' guidelines in $1998,{ }^{7}$ the UK National Service Framework for CHD in 2000, ${ }^{39}$ and the publication of other trials such as the 1998 Long-Term Intervention with Pravastatin in Lipid Disease trial, ${ }^{16}$ and the 2002 and 2003 publications from the Medical Research Council/British Heart Foundation Heart Protection Study, ${ }^{20,21}$ together with the UK expiry of the simvasatin patent in May 2003.

The particularly high relative increase in the number of HDL cholesterol tests requested (Figure 2)
Figure 4. Mean total serum cholesterol levels, with standard deviation (SD) bars, for individuals with one to six or more tests during each 3-year period. Overall mean values are diagnosis (one or two tests per period; solid line joining circles) and for those tested for monitoring purposes (three or more tests per period; dotted line joining triangles). shown for those tested for

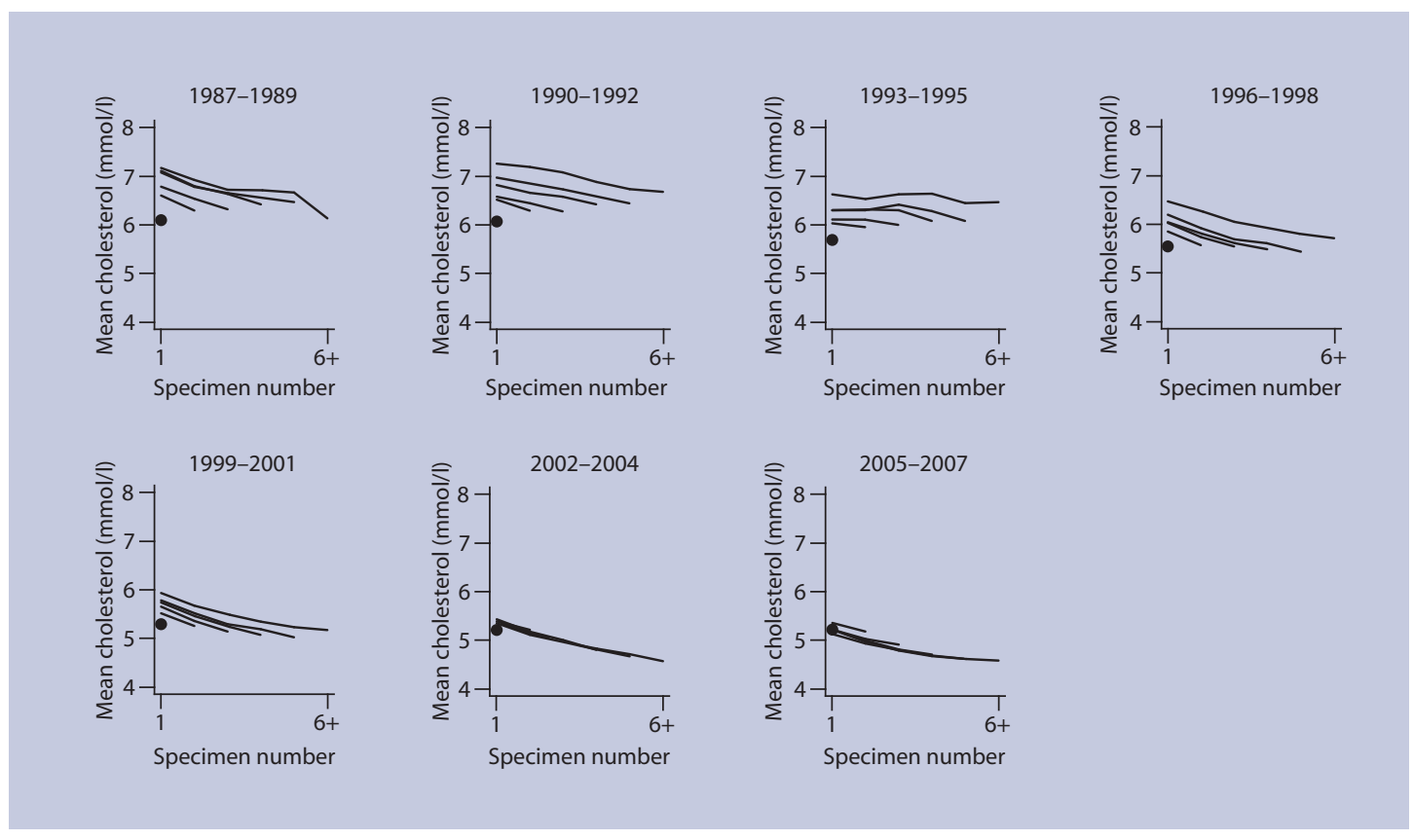

Figure 5. Mean total serum cholesterol levels at each test for patients with one (circle) to 6 or more tests (subsequent test values joined by a solid line) during each 3-year period. The six lines in each graph represent the number of tests during each 3-year period. 
may reflect the use of the total-to-HDL cholesterol ratio as the risk-prediction tool in the 1998 Joint British Societies' guidelines, ${ }^{7}$ which first appeared as an appendix in the British National Formulary in 2000. The introduction of the Quality and Outcomes Framework (QOF) in April 2004, and its adjustment in April 2006, appeared to precede a slowing of the increase in cholesterol testing and its reduction, respectively.

Mean blood cholesterol levels in 2005-2007 were slightly lower than the published 2006 mean blood cholesterol levels for males and females aged 16 years and over in the whole of England (5.3 and $5.4 \mathrm{mmol} / \mathrm{l}),{ }^{8,40}$ which probably reflects a regional effect. $^{8}$ The levels are, however, close to those suggested by the National Service Framework for $\mathrm{CHD}$ of a cholesterol target of $<5.0 \mathrm{mmol} / \mathrm{l}$ for both primary and secondary prevention of CHD. ${ }^{39}$ More recent guidelines suggest a target for total cholesterol of $<4.0 \mathrm{mmol} / \mathrm{l}$ for high-risk individuals. ${ }^{41}$

\section{Implications for future research and clinical practice}

Patients who do not comply with treatment regimes constitute around $25 \%$ of those prescribed statins in primary care, ${ }^{42}$ and up to $85 \%$ of those who have received more than 5 years of therapy. ${ }^{43}$ Regular checks can be used to monitor and enhance compliance as well as assess the success of the prescribed therapy, ${ }^{41}$ and associated lifestyle interventions, such as dietary modification and increased exercise. ${ }^{44}$ While any reduction in frequency would need to be undertaken in the context of associated patient-centred prevention strategies, ${ }^{45}$ the large proportion of tests for monitoring estimated to have been conducted in recent years is likely to reflect current treatment guidelines which recommend frequent monitoring of lipid levels for patients on lipid-lowering therapy. ${ }^{26}$ This frequency has recently been questioned using data from large treatment trials, ${ }^{6,27}$ although these observations have yet to impact on treatment guidelines. While the QOF requirement for patients on 'at risk' registers to have one annual cholesterol test may be a barrier to evidence-based change in practice, there is some evidence from this study that the QOF curtailed the rapid increase in cholesterol testing.

There appears to be considerable over-monitoring that may not benefit patients, while also straining laboratories and incurring considerable economic costs to the NHS and personal costs to patients. The current NHS system, whereby the local primary care trust pays laboratories for testing on behalf of their practices, and where most of the tests are done under a block contract that only partially reflects activity, does not necessarily encourage GPs to limit their use of this resource. The rise over the last two decades in the proportion of tests for monitoring, combined with the estimated large proportion of all tests that may be unnecessary, suggest there may be scope in some stable patients to reduce the volume of lipid testing, with potential benefits for the NHS, laboratories, and clinicians, and, moreover, for the individual patients.

\section{Funding body}

This work was supported a National Institute for Health Research Programme Grant.

\section{Ethics committee}

The National Research Ethics Service confirmed that the study was service audit and therefore did not require ethical approval.

\section{Competing interests}

The authors have stated that there are none.

\section{Acknowledgements}

Our thanks to Rod Jackson, David Mant, Dan Lasserson, Andrew Neil, and Jeffrey Aronson for helpful comments on drafts and analyses during the preparation of this paper.

\section{Discuss this article}

Contribute and read comments about this article on the Discussion Forum: http://www.rcgp.org.uk/bjgp-discuss

\section{REFERENCES}

1. Fowkes FGR. Containing the use of diagnostic tests. Br Med J (Clin Res Ed) 1985; 290(6467): 488-490.

2. Bates DW, Boyle DL, Rittenberg E, et al. What proportion of common diagnostic tests appear redundant? Am J Med 1998; 104(4): 361-368.

3. Van Walraven C, Naylor CD. Do we know what inappropriate laboratory utilization is? A systematic review of laboratory clinical audits. JAMA 1998; 280(6): 550-558.

4. Weydert JA, Nobbs ND, Feld R, Kemp JD. A simple, focused, computerized query to detect overutilization of laboratory tests. Arch Pathol Lab Med 2005; 129(9): 1141-1143.

5. Van Walraven C, Raymond M. Population-based study of repeat laboratory testing. Clin Chem 2003; 49(12): 1997-2005.

6. Glasziou PP, Irwig L, Heritier S, et al; LIPID Study Investigators. Monitoring cholesterol levels: measurement error or true change? Ann Intern Med 2008; 148(9): 656-661.

7. Joint British recommendations on prevention of coronary heart disease in clinical practice. Heart 1998; 80(Suppl 2): S1-S29.

8. British Heart Foundation Statistics Database. Coronary heart disease statistics, 2008. http://www.heartstats.org (accessed 7 Jun 2010).

9. Stamler J, Vaccaro O, Neaton JD, et al, for the Multiple Risk Factor Intervention Trial Research Group. Diabetes, other risk factors and 12-year cardiovascular mortality for men screened in the multiple risk factor intervention trial. Diabetes Care 1993; 16(2): 434-444.

10. Breuer HM. Low density lipoprotein cholesterol and coronary heart disease — lower is better. Eur Cardiol 2005; http://www.touchcardiology.com/files/article_pdfs/5273.pdf (accessed 7 Jun 2010).

11. Residual Risk Reduction Initiative, R3i. New insights link low HDLcholesterol and elevated triglycerides with coronary heart disease and microvascular complications in patients at goal for ldl-cholesterol. 2009. http://www.prnewswire.com/mnr/r3i/39757/ (accessed 7 Jun 2010).

12. Friedewald WT, Levy RI, Fredrickson DS. Estimation of the concentration of low-density lipoprotein cholesterol in plasma, without use of the preparative ultracentrifuge. Clin Chem 1972. 18(6): 499-502.

13. Baigent C, Keech A, Kearney PM, et al; Cholesterol Treatment Trialists' (CTT) Collaborators. Efficacy and safety of cholesterollowering treatment: prospective meta-analysis of data from 90056 participants in 14 randomised trials of statins. Lancet 2005; 366(9493): 1267-1278.

14. Scandinavian Simvastatin Survival Study Group. Randomised trial of cholesterol lowering in 4444 patients with coronary heart disease: 
the Scandinavian Simvastatin Survival Study (4S). Lancet 1994; 344(8934): 1383-1389.

15. Shepherd J, Stuart M, Cobbe M, et al, for the West of Scotland Coronary Prevention Group. Prevention of coronary heart disease with pravastatin in men with hypercholesterolemia. N Engl J Med 1995; 333(20): 1301-1307.

16. The Long-Term Intervention with Pravastatin in Ischaemic Disease (LIPID) Study Group. Prevention of cardiovascular events and death with pravastatin in patients with coronary heart disease and a broad range of initial cholesterol levels. N Engl J Med 1998; 339(19): 1349-1357.

17. Pedersen T, Kjekshus J, Pyörälä K, et al. Effect of Simvastatin on Ischemic Signs and Symptoms in the Scandinavian Simvastatin Survival Study. Am J Cardiol 1998; 81(3): 333-335.

18. Effective Health Care. Cholesterol and coronary heart disease: screening and treatment. York: NHS Centre for Reviews and Dissemination, 1998.

19. Department of Health. National service framework for coronary heart disease. London: Department of Health, 2000.

20. Collins R, Armitage J, Parish S, et al. MRC/BHF Heart Protection Study of cholesterol lowering with simvastatin in 20536 high-risk individuals: a randomised placebo-controlled trial. Lancet 2002; 360(9326): 7-22.

21. Collins R, Armitage J, Parish S, et al. MRC/BHF Heart Protection Study of cholesterol lowering with simvastatin in 5963 people with diabetes: a randomised controlled trial. Lancet 2003; 361(9374): 2005-2016.

22. Sacks FM, Pfeffer MA, Moye LA, et al, for the Cholesterol and Recurrent Events Trial Investigators. The effect of pravastatin on coronary events after myocardial infarction in patients with average cholesterol levels. N Eng J Med 1996; 335(14): 1001-1009.

23. Editorial. OTC Statins: a bad decision for public health. Lancet 2004 363(9422): 1659.

24. University College London Hospitals. UCLH guidelines on statin prescribing. http://www.uclh.nhs.uk/ourservices/servicea$\mathrm{z} / \mathrm{css} / \mathrm{pmm} /$ documents/uclh\%20guidelines\%20on\%20statin\%20pres cribing.pdf

25. National Institute for Health and Clinical Excellence. Statins for the prevention of cardiovascular events. London: National Institute for Health and Clinical Excellence, 2006

26. National Heart, Lung, and Blood Institute. Third report on the National Cholesterol Education Program (NCEP) expert panel on detection, evaluation, and treatment of high blood cholesterol in adults (Adult Treatment Panel III). Bethesda, MD: US Department of Health and Human Services, 2001.

27. Takahashi O, Glasziou PP, Perera R, et al. Lipid re-screening: what is the best measure and interval? Heart 2010; 96(6): 448-452

28. $\mathrm{R}$ version 2.10.0. The $\mathrm{R}$ Project for Statistical Computing. http://www.r-project.org (accessed 7 Jun 2010).

29. Singer JD, Willett JB. Applied longitudinal data analysis: modeling change and event occurrence. Oxford: Oxford University Press, 2003.

30. Packard CJ, Bell MA, Eaton RH, et al. A pilot scheme for improving the accuracy of serum cholesterol measurement in Scotland and Northern Ireland. Ann Clin Biochem 1993; 30(Pt 4): 387-393.

31. Oliver MF. Doubts about preventing coronary heart disease. $B M J$ 1992; 304(6824): 393-394.

32. Davey Smith G, Pekkanen J. Should there be a moratorium on the use of cholesterol lowering drugs? BMJ 1992; 304(6824): 431-434.

33. Oliver MF. Might treatment of hypercholesterolaemia increase noncardiac mortality? Lancet 1991; 337(8756): 1529-1531.

34. Manolio TA, Ettinger WH, Tracy RP, et al, for the CHS Collaborative Research Group. Epidemiology of low cholesterol levels in older adults: The Cardiovascular Health Study. Circulation 1993; 87(3): 728-737.

35. Castelli WP, Anderson K, Wilson PW, Levy D. Lipids and risk of coronary heart disease. The Framingham Study. Ann Epidemiol 1992; 2(1-2): 23-28.

36. Kornitzer M, Rose G. WHO European Collaborative Trial of multifactorial prevention of coronary heart disease. Prev Med 1985 14(3): 272-278.

37. Robertson TL, Kato H, Rhoads GG, et al. Epidemiologic studies of coronary heart disease and stroke in Japanese men living in Japan, Hawaii and California. Incidence of myocardial infarction and death from coronary heart disease. Am J Cardiol 1977; 39(2): 239-243.

38. Shepherd J. Cholesterol lowering with statins: how WOSCOPS confounded the skeptics. Atheroscler Suppl 2007; 8(2): 9-12.

39. Department of Health. National service framework for coronary heart disease. London: Department of Health, 2000.

40. Joint Health Surveys Unit. Health Survey for England 2006. Cardiovascular disease and risk factors. Leeds: The Information Centre, 2008.

41. British Cardiac Society, British Hypertension Society, Diabetes UK, HEART UK, Primary Care Cardiovascular Society, The Stroke Association (2005). JBS2: Joint British Societies' guidelines on prevention of cardiovascular disease in clinical practices. Heart 2005 91(Suppl V): v1-v52.

42. Howell N, Trotter R, Mottram DR, Rowe PH. Compliance with statins in primary care. Pharm J 2004; 272(7281): $1-40$

43. Jacobson TA. The forgotten cardiac risk factor: noncompliance with lipid-lowering therapy. Medscape Cardiology 2004; 8(2). http://www.medscape.com/viewarticle/496144 (accessed 7 Jun 2010).

44. North West London Cardiac Network. Guidance on prescribing of statins in primary \& secondary care across NW London. London: North West London Cardiac Network, 2006. http://www.nwlcn.co.uk/pdfs/amendedfinalstatinpresguide41207.pd $\mathrm{f}$ (accessed 7 Jun 2010).

45. Taubert KA, Clark NG, Smith RA. Patient-centred prevention strategies for cardiovascular disease, cancer and diabetes. Nat Rev Cardiol 2007; 4(12): 656-666. 